\title{
7. Diversity of youth policy regimes and early job insecurity - towards an integrated approach
}

\section{Ondřej Hora, Markéta Horáková and Tomáš Sirovátka}

\section{INTRODUCTION}

Young people have been disproportionately affected by job insecurity, as indicated by the prevalence of youth unemployment, inactivity, job precariousness and fragmented careers during the economic crisis of 2008 and beyond. The governments of many European countries have acknowledged this problem and have addressed it in their education, employment and social policies. Similarly, since 2010, the EU has stepped up its efforts to reduce youth unemployment and increase youth employment in member states. The most important EU initiatives have been:

- Youth on the Move, a package of education and employment measures (2010), including the Youth Opportunities Initiative (2011; aimed at cutting youth unemployment) and Your First EURES Job (to enhance youth mobility within Europe);

- Youth Employment Package (2012), including the Youth Guarantee (2013; see Dingeldey et al., Chapter 9 this volume), the Quality Framework for Traineeships (2014) and the European Alliance for Apprenticeships;

- Youth Employment Initiative (2013), focused on supporting young people who are not in employment, education or training;

- European Solidarity Corps (2016), allowing youth to volunteer or work in projects to the benefit of disadvantaged communities or groups around Europe;

- Finally, from 2013, new regulations for the European Structural Funds have reinforced the priority of supporting the employability and employment of young people (see Bussi et al., Chapter 10 this volume). 
However, few studies have sought to assess the results of these reforms and initiatives. There is limited knowledge about how policies at national level have shaped specific 'youth policy regimes' (Wallace and Bendit, 2009), 'youth (un)employment regimes' (e.g., Cinalli and Giugni, 2013; Gallie and Paugam, 2000a, 2000b) or the extent to which European policies have influenced such regimes. In current comparative research, however, emerging typologies of youth employment regimes have proved to be useful heuristic tools. Such typologies enable us to capture the complex interactions between the key social institutions - the market, the family and the welfare state - and relate them to outcomes such as social inequality and poverty amongst young people. Avdagic (2015) has argued that the effect of one particular measure can depend on the overall institutional set-up and on the interaction between the labour market, social policy, skill regimes and product markets.

In this chapter we discuss what might be the distinctive features of 'youth employment/school-to-work transition regimes'. Our specific contribution to the debate is an examination of the interactions between four public policy fields: education, active employment policies, employment protection legislation (EPL) and unemployment income protection. We address two questions: (1) What do existing studies of policies for young people tell us about the patterns of policy packages that include measures in the above-mentioned policy fields? and (2) How well do these different policy packages protect young people against the risks of early job insecurity? We assume that institutional regulations and labour market interventions represent crucial conversion factors that shape opportunity structures for young people as well as their scope for active agency in the labour market.

\section{THE GENERAL CONTEXT: VARIETIES OF CAPITALISM AND PRODUCTION REGIMES}

The production regime theory/varieties of capitalism approach (Hall and Soskice, 2001) stresses the role of system coordination and institutional complementarities. The approach distinguishes between two production regimes: the coordinated market economy (CME), which is dependent on non-market relations, collaboration, credible commitments and deliberative calculation on the part of firms, and the liberal market economy $(L M E)$, which is shaped by competitive relations, competition and formal contracting, as well as a direct link between supply and demand in line with price signalling. In the CME regime, the institutions of collective bargaining play an important role in shaping economic and labour market performance, as indicated by high union density and coverage, as well as 
by the bargaining power of trade unions, often supported by legislative and/or institutional arrangements.

The CME regime builds on 'specific or co-specific assets', whose value depends on the active cooperation of others, whereas LMEs build on the centrality of 'switchable assets', which can be realized if they are diverted to multiple purposes (Hall and Soskice, 2001). This means that the distinction between coordinated and liberal market economies implies a contrast between specific- and general-skill systems. Whereas coordinated market regimes foster higher and more specialized skills as a result of stronger vocational training (both prior to and after full entry into the labour market), liberal market regimes depend on general skills acquired through the school system (Gallie, 2011).

Furthermore, in LMEs the skills of the workforce are highly polarized, and the workforce is under unilateral managerial control. The protection of the workforce is generally weak given the marginalized position of trade unions, as well as weak EPL and unemployment income protection. In contrast, CMEs are based on a highly skilled workforce who are relatively autonomous in performing their tasks and are well protected; there is also strong EPL and unemployment income protection, resulting in higher security for the workers, who are valued for their skills (Gallie, 2007a).

At the same time, other research has identified four policy fields as being most relevant for shaping young people's chances on the labour market: education, employment protection, unemployment income protection and ALMP (Chung and Van Oorschot, 2011; Cinalli and Giugni, 2013; Clark and Postel-Vinay, 2009; Walther, 2006). In this chapter we discuss these four policy areas and their potential synergies.

The chapter aims to develop a perspective that takes policy packages into account and can help us to understand the extent to which different 'transition regimes' related to school-to-work transitions and employment are able to support young people dealing with early job insecurity.

\section{FOUR POLICY FIELDS INVOLVED IN YOUTH TRANSITION REGIMES}

\subsection{Education and Training}

Labour market theories, specifically the concept of labour market segmentation and signalling theory, emphasize the type and level of education as a crucial factor affecting young people's transitions into employment. Gangl (2001) describes decisive differences between occupationalized and nonoccupationalized systems. Occupationalized systems (occupational labour 
markets) are those organized around occupations, which are clearly defined by standardized qualification and entry requirements, whereas non-occupationalized systems (internal labour markets) are organized around less clearly defined enterprises and occupational boundaries (Raffe, 2011). In other words, education in occupationalized systems is highly standardized and completed with certificates that are familiar to all the actors; by contrast, education in non-occupationalized systems tends to be less standardized and more flexible and fragmented. Young people's entry into the labour market in occupationalized systems is generally faster and easier (based on skill specificity); conversely, in nonoccupationalized systems, entry may take longer (based on the level of education) but be more flexible as young people move up the occupational ladder and between types of education (Raffe, 2011).

Looking at patterns of school-to-work transitions, Raffe (2011) has contrasted two types of transition system. In the first type transitions into employment tend to be smoother and more predictable, with a stronger correlation between education and labour market destinations, as well as a lower risk of unemployment. In this transition pattern, stratified and standardized education systems offer progressive specialization into occupationally specific streams with only little opportunity to change direction/ specialization. In the second type of transition system there is clearly greater flexibility in entering the labour market and more opportunity for occupational or career mobility. This transition pattern is characterized by a less standardized, less stratified and more flexible education system, although there are rather weak links between education and the labour market.

Pohl and Walther (2007) have developed the most comprehensive theory of youth transition regimes, exploring how cross-country differences in school-to-work transitions are systematically related to the way in which education systems are organized. They argue that smooth transitions of young people from education to the labour market are achieved through synergic functioning of some key institutional and policy domains: the structure of education and training systems, features of employment regulation regimes and social security systems, and provisions of labour market activation. Education and training are regarded as the key institution affecting young people's transitions. Nevertheless, their significance differs depending on the kind of education and training that is emphasized (vocational specificity), the universality or selectivity of educational measures, and the degree of flexibility of the education systems (Lundahl, 2011).

The universal youth transition model is characterized by a comprehensive and inclusive education system, with many diversified post-compulsory routes into general and vocational education. Smooth transitions of young 
people into employment are strengthened by the relatively close involvement of employers in the process of specifying and delivering training, as well as by the provision of early activation underpinned by strong human capital investment and a personalized approach (Hadjivassiliou et al., 2016).

The employment-centred transition regime is typical for highly selective and standardized education and training systems with well-developed apprenticeships and national certifications (Hadjivassiliou et al., 2016). The dual system of education builds on alternating between workplace training and education in public institutions. The system is closely connected to occupational labour markets where occupations are clearly defined through standardized qualifications and entry requirements. As a result, the employment-centred model tends to foster structured and relatively rapid and smooth transitions from education to employment. On the other hand, although young people achieve adult working patterns relatively quickly, their pace of upward mobility is slower compared to other transition regimes (Raffe, 2011).

In the liberal youth transition regime the system of education is quite comprehensive, with high degrees of flexibility and fragmentation in post-compulsory education (Hadjivassiliou et al., 2016). Education is focused on general skills obtained mainly through academic channels and provided by state-run as well as private education institutions. Vocational education plays only a minor role: participation in vocational education is low and the proportion of early school-leavers is high (West and Nikolai, 2013). The delivery models of vocational education are not standardized and employer involvement in the provision of vocational education is rather weak. This model is often linked to internal labour markets where entry into employment is based on levels of attainment rather than specific skills, with young people remaining at the back of the queue for jobs (Raffe, 2011). Accordingly, youth transitions from education to the labour market are likely to be complicated, insecure and 'fractured'.

Countries associated with the sub-protective (Mediterranean) transition regime have stratified, centrally standardized, non-selective and comprehensively structured compulsory education systems, with a weak role for vocational education and training, which is rather underdeveloped and of low quality (Hadjivassiliou et al., 2016). As a result, educational outcomes as well as transition patterns are more likely to be polarized, including high rates of early school-leaving. Transitions (at least those for low and medium-level qualifications) are complicated and slow because of the weak linkage between education and the labour market (West and Nikolai, 2013).

In countries characterized by the transitionallpost-socialist transition regime, there may be comprehensive compulsory education systems where post-compulsory general education is more popular than vocational educa- 
tion. This is partly a consequence of the historically poor reputation of vocational education and its excessive rigidity (Hadjivassiliou et al., 2016), also because of the poor quality of vocational programmes and their weak linkage to the needs of employers. The set-up of vocational education varies amongst the post-socialist countries, with the school-based programmes generally being favoured. Consequently, there is a considerable skills mismatch, resulting in difficult and insecure transitions for youth into employment.

Some authors (e.g., Lundahl, 2011) have emphasized that, in reality, contemporary education systems may contain elements of two contrasting paradigms at the same time. First, there is the universalistic paradigm, according to which education systems are complex, standardized and open to each individual (the inclusiveness and acceptance of individual differences being the crucial values of such systems). Second, there is the liberal paradigm, which tends to stress the link between education and the market (emphasizing the roles of competition and individual success on the labour market).

Schofer and Meyer (2005) and Bathmaker (2003) have discussed the expansion of (higher) education in recent decades as one of the main structural characteristics of the social context in which youth transitions are realized. They conclude that, despite the general trend towards the expansion of education (arising, amongst other factors, from the development of lifelong learning principles), individual countries differ in the speed and extent of such expansion. In systems where the share of more highly qualified people is growing fastest, signs of qualification inflation are becoming increasingly apparent. In these countries, access to the labour market becomes ever more difficult for a broader group of (qualified) young people (Brown et al., 2011).

Finally, an indicator of education policy efforts might also be investments into education systems and institutions by the state and other relevant actors. As Iversen and Stephens (2008) have shown, in some countries education is well funded, with a strong emphasis on the principles of public redistribution, broad access and the quality of the programmes provided (especially countries in the universal and employment-centred regimes). Conversely, in other countries there may be underfunding of education systems, as well as less effective mechanisms for allocating public funds (i.e., countries in the transitional/post-socialist and sub-protective clusters).

To sum up, despite some trends towards convergence, education systems still differ across Europe along at least three key dimensions. The first is the degree of vocational specificity, or the extent to which education provides students with vocational skills and occupational identities, as well as the scale of higher education (Bol and Van de Werfhorst, 2013; Raffe, 2011). Another important aspect here is the form and intensity of 
vocational training related to specific occupations (Eichhorst et al., 2015). Education-to-employment transitions are considered to be smoother in employment-centred than in other regimes. This is because of the high degree of occupational specificity of educational qualifications, the existence of an apprenticeship system, employer involvement in the design of curricula and/or the leaving conditions at vocational schools (Gangl, 2001).

The second dimension is the stratification of educational opportunity, or the form and extent of inter-programme tracking with an impact on the grouping of students based on ability (Bol and Van de Werfhorst, 2013). In stratified education systems (i.e., systems in employment-centred regimes, where students are separated early into vocational and academic tracks upon entering secondary schools and have only little opportunity to move between tracks) there is a closer link between education and a differentiated occupational structure (Raffe, 2011). For these reasons, youth transitions are expected to be easier.

The standardization of education provision (i.e., the extent to which there is nationwide uniformity in school quality standards with respect to curricula and school-leaving qualifications) is the third and final dimension for classifying education systems. Transitions into the labour market are considered to be smoother and faster in standardized systems (typical for the employment-centred model) because employers can rely on the information in standardized certificates and new entrants can be matched with suitable jobs without repeated job changes (Raffe, 2011).

\subsection{Active Labour Market Policies and Activation}

Gallie (2007a, 2007b, 2013) has adopted two different perspectives when distinguishing between different employment regimes. The first concentrates on the relative power resources of employers and employees, and the emergent systems of employment regulation. The analytical categories capture, first, to what extent the market is regulated by the social partners (employers and the state). This points to the broad distinction between inclusive systems of employment regulation, where policies are designed to protect vulnerable sectors of the workforce; dualist systems, where there is a relatively sharp distinction between core and peripheral workers; and liberal systems, where work conditions depend primarily on market forces (Gallie, 2013: 13). Inclusiveness involves two principal dimensions: the scope of collective bargaining (indicated by bargaining coverage) and its depth (indicated by union density). More specifically, 'inclusive employment regimes are those that aim to extend both employment and common employment rights, and in which organised labour is well institutionalised. Dualist regimes are less concerned about overall employment levels, but they guarantee strong 
rights to a core workforce of skilled long-term employees, at the expense of poor conditions and low security of the periphery' (Gallie, 2007a: 17).

In this typology the Nordic countries were associated with the inclusive regime; the continental and the Southern European countries with the dualist regime; and the Anglo-Saxon countries with the liberal regime. Gallie (2013: 22-3) saw the Eastern European countries (except Slovenia) as being associated with a less inclusive liberal regime.

From another perspective, when assessing the welfare generosity extended to the unemployed both in passive and active labour market policies, a distinction was made between universalistic, employment-centred, liberal and sub-protective regimes. Originally, Gallie and Paugam (2000a, $2000 \mathrm{~b}$ ) focused on how much effort is invested in income protection and ALMPs in the specific regime, distinguishing between four unemployment regimes: ${ }^{1}$ (1) sub-protective, where active employment policy is quasi nonexistent; (2) liberal/minimal, where active employment policy is weak; (3) employment-centred, where active employment policy is extensive; and (4) universalistic, where active employment policy is very extensive. The effort invested in ALMP was indicated by expenditure as a percentage of GDP. The highest level of effort is apparent in the Nordic/universalistic regime; there is a somewhat lower level in the continental (dualist) regime; this is followed by the liberal and southern/sub-protective regimes, although the differences are not as remarkable as they were in the past (see Gallie and Paugam, 2000a, 2000b). The transitional/post-socialist countries score much lower (Gallie, 2013: 24), which is probably why they were classified as an extreme version of the sub-protective regime.

The literature dealing with the active labour market and activation policies has distinguished between two stylized 'model approaches' to activation, expressed in the following ways: a workfare approach versus an insertion approach (Lødemel and Trickey, 2001) or a workfare approach versus 'Nordic' productivism (Esping-Andersen, 1999); and demanding versus enabling approaches (Eichhorst et al., 2008) or a work-first approach versus an enabling approach (Dingeldey, 2007). The work-first approach, which seeks to quickly insert the unemployed into jobs, emphasizes their duty to accept any job or work programme, irrespective of its quality or suitability. Nominal and wage labour flexibility (Standing 2000) is a key adjustment mechanism in a deregulated labour market. The enabling/ human capital-development approach aims to support the unemployed in finding and keeping a suitable, meaningful job, underpinned with skills and capabilities that imply a social investment strategy by employers and/

1 The features of income protection in the (un)employment regimes are distinguished in the section on unemployment protection. 
or the state. The skills/work competences and capabilities of employees are enhanced, and organizational adjustments are made.

For the work-first approach, incentive reinforcement (positive and negative incentives to work) and employment assistance (facilitating [re] entry into the labour market) are the most important instruments used to quickly place people in any jobs available (Bonoli, 2010). Upskilling is most important for the enabling/human-capital development approach, although employment assistance (individual counselling and casework) also plays a role as a positive incentive. Occupation/job creation may be used in both approaches, however, depending on what the job offers are. While in the work-first approach activation/workfare schemes or work on trial or short-term placements combined with back-to-work benefits are the typical instruments, in the enabling/human-capital development approach, job subsidies enable placement in permanent-contract (quality) jobs and/or opportunities to gain the work experience and skills needed for job tenure. In reality, ALMPs and activation strategies usually include elements of both approaches ('contingent convergence'), where demanding and enabling measures are mixed (Eichhorst et al., 2008).

Policy integration takes place through coordination between local, regional, national and supranational policymaking levels (vertical coordination), whereas horizontal coordination involves various policy sectors and actors, such as public, private and non-profit stakeholders. The complexity of the policies and the need for coordination increase, with emphasis being put on an enabling approach that aspires to responding to the heterogeneous and complex needs of the vulnerable groups of unemployed. These enabling approaches include individualized, holistic and needs-oriented policies that presume closer cooperation between stakeholders and better coordination.

To conclude, the overview of the existing literature on employment regimes suggests that these regimes differ in their overall policy effort in terms of the instruments used and the modes of governance. Table 7.1 presents a stylized typology that builds on Gallie (2013) and Bonoli (2010).

\subsection{Employment Protection Legislation}

EPL is usually defined as a set of legally obligatory norms for the behaviour of actors in the labour market involved in the hiring and firing of workers. These may include trial periods, notice periods, severance payments and other similar procedures. Many researchers relate EPL to firms' actual hiring and firing practices, affecting firms' productivity, workers' commitment, turnover and firm-specific/general employment levels (Barbieri and Cutuli, 2015; Clark and Postel-Vinay, 2009; Harcourt et al., 2007; Noelke, 2016). Changes in EPL may affect both the micro 


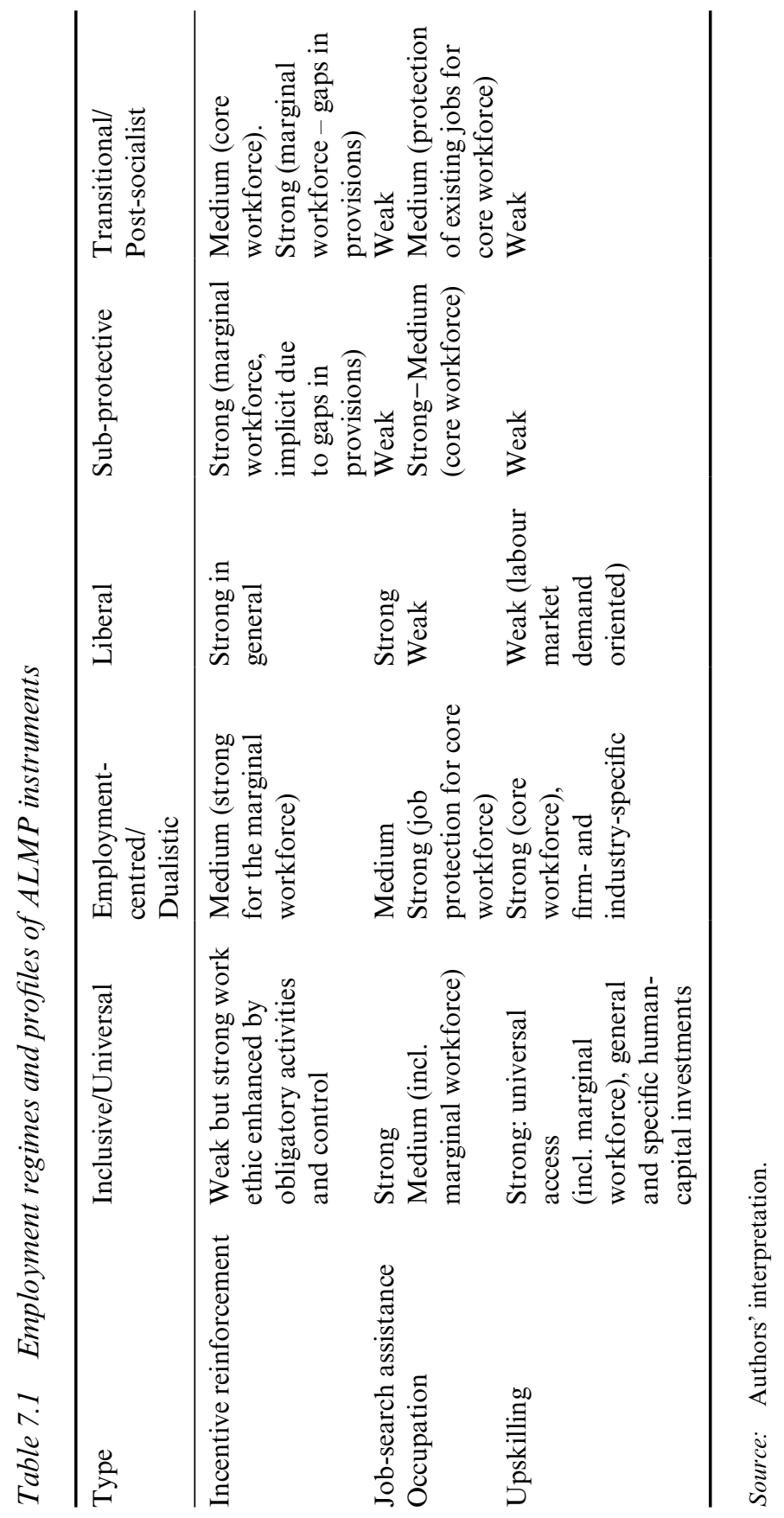


and macro levels (Barbieri and Cutuli, 2015). The precise definition of the employment protection concept is crucial. Many studies use general constructs, such as the OECD composite EPL index, which may hamper understanding of the concrete aspects that are relevant for workers (see Gebel and Giesecke, 2016; Noelke, 2016; Scarpetta, 2014).

On the individual level, EPL is expected to be advantageous for employees because '[1] egislated employment protection obviously helps to provide workers with some assurance that their jobs are reasonably secure and will not be taken away from them in the absence of due process, compensation, and some advance warning' (Harcourt et al., 2007: 968). Strict EPL carries potential risks for employers, including prolonged employment of non-productive or misbehaving employees - known as the 'lethargy effect' (Harcourt et al., 2007). Changes in EPL can be attributed to changes in power structures regarding employers in society in the last quarter of the twentieth century (Harcourt et al., 2007).

Institutions do not necessarily protect all workers equally (Chung, 2016). Some authors highlight the relative perspective: the disadvantaged position of young people when compared to other groups or standards in a country or compared to previous eras. In most continental countries there has been a strategy since the late 1980s of weakening EPL for workers on the secondary labour market (reducing protection for those with temporary contracts), while maintaining high EPL for core workers. This has created labour market segmentation and may have given rise to new forms of economic and social inequality (Barbieri and Cutuli, 2015; Berloffa et al., 2016; Chung, 2016; Gebel and Giesecke, 2016; Noelke, 2016). There is a general assumption and also evidence that this has led to the substitution of permanent jobs with temporary jobs, as well as reduced mobility from temporary to permanent employment (see Barbieri and Cutuli, 2015; Chung, 2016; Gebel and Giesecke, 2016; Noelke, 2016).

The discussed effects of EPL primarily concern the level and structure of employment and unemployment. While countries with higher levels of EPL (usually CME countries) seem to have longer job durations (Harcourt et al., 2007), the relationship between EPL and the level of unemployment seems to be ambiguous at the theoretical and empirical levels. On the one hand, EPL may reduce unemployment by making it difficult for employers to fire workers (Breen, 2005). On the other, high EPL raises the potential costs of job loss (Clark and Postel-Vinay, 2009). In other words, it is expected that low or reduced EPL will increase employment chances, especially for people who are less connected to the labour market (such as young graduates) and may change the composition of unemployment (Barbieri and Cutuli, 2015; Breen, 2005). Many young workers and those with intermittent careers risk becoming trapped 
in temporary contracts, finding it considerably difficult to move to more stable contracts (Scarpetta, 2014).

While previous studies have shown negative effects of EPL on unemployment (see Berloffa et al., 2016), more recent studies have usually found no or only slightly negative effects (Avdagic, 2015; Breen, 2005; Noelke, 2016; Scarpetta, 2014). One assumption is that the influence of EPL is more apparent in the composition of unemployment than in the level of unemployment (Barbieri and Cutuli, 2015). According to another line of reasoning, the youth unemployment rate is ambiguously affected by EPL because there may be other effects working in the opposite direction (Avdagic, 2015; Gebel and Giesecke, 2016; Noelke, 2016). Building on empirical findings, Gebel and Giesecke (2016) and Noelke (2016) have disputed the idea that high levels of EPL had led to high levels of youth unemployment and that recent reforms had helped to lower levels of youth unemployment. Others have argued that there are factors such as the functioning of the education system (Avdagic, 2015; Breen, 2005), the general economic situation, collective bargaining (Avdagic, 2015) or the implementation of ALMP (Gebel and Giesecke, 2016) that contribute equally or even more substantially to the general level of youth unemployment.

The central question for many researchers (e.g., Barbieri and Cutuli, 2015) has been whether jobs in the secondary labour market are stepping stones to more stable and secure employment, or whether they lead to repeated spells of short-term employment and prolonged 'scarring effects'. The results of empirical studies differ according to the research design and groups compared (descriptive without comparison, comparison with permanent contracts, comparison with unemployed), and to the (clusters of) analysed countries (Gebel, 2013). Gebel (2010) showed that in some countries, when compared to permanent contracts, there are (diminishing) negative effects of temporary contracts on future wages and the level of unemployment. Barbieri and Cutuli (2015) found both a scarring effect of unemployment and a (weaker) scarring effect of temporary employment on the future chances of permanent employment. Thus, it would be better to take a temporary job than to remain unemployed (Gebel, 2013). These effects are of different magnitudes in the different clusters of countries. People living in countries in Southern Europe have much worse labour market chances than people in Central and Northern Europe (Barbieri and Cutuli, 2015). Other research has shown that changing temporary contracts can lock young people into the segmentation trap (see Barbieri and Cutuli, 2015; Berloffa et al., 2016).

Clark and Postel-Vinay (2009), Chung and Van Oorschot (2011) and Chung (2016) have discussed the relationship between EPL and the employment security of workers. Their conclusion is that people in countries with more stringent EPL feel less secure in private jobs than 
in countries with less stringent EPL. This is probably because high EPL in countries like Spain and Greece has been associated within the same setting with bad economic situations, low benefit generosity and a low investment in ALMP (Chung, 2016; Clark and Postel-Vinay, 2009). According to Chung (2016), people in countries with higher union density and institutional dualization feel more secure in permanent jobs; people on temporary contracts are relatively more exposed to insecurity, but not more than people in other countries. The difference is in the position of the insiders, not that of the outsiders.

Two arguments explain the differences in the use of EPL. First, according to Gallie (2007a, 2007b), in the countries where specific skills are important, employers are reluctant to casually hire and fire employees because of training costs and the need to maintain good relations with the workforce. However, employers in liberal countries need to take advantage of the short notice of new skills on the labour market, which requires a regulative system that allows employers to hire and fire employers at low cost. The second argument is related to the need for employers to use non-standard contracts as a screening device to assess the skills of new employees.

Although inclusive employment regimes are universalistic and provide support for labour market integration, such countries may have various levels of EPL when compared to each other, but similar levels within a given country. Polarization tendencies are usually strongly contained. In the employment-centred regime, strong rights are guaranteed to the core workforce, although the periphery is not protected from vulnerability or low employment security. In the liberal market regime, employment conditions are regarded as a concern of individual employers. This regime emphasizes minimal employment regulation for all workers and differences between contracts are usually small. In sub-protective regimes, we expect very strong protection of the core workforce, and especially strong protection at the end of the individual contract or in the case of collective dismissals. This creates a 'closed system', while young people often work in temporary or informal jobs (Walther, 2006). In the transitional/postsocialist regimes, the level of employment protection was significantly reduced in the 1990s and is probably below the EU average for all types of contracts (Cazes and Nesporova, 2004). For transitional/post-socialist countries, the level of law enforcement is even more important than the legislated level of employment protection (Cazes and Nesporova, 2004).

\subsection{Unemployment Income Protection}

The main role of unemployment protection is seen in income protection against poverty and material deprivation during transitions between 
various economic statuses (education, employment, etc.) and in periods of economic downturn. Unemployment protection is thus an important source of income security (Standing, 2000). In most countries there are at least two quite distinct schemes of protection - unemployment insurance and social (unemployment) assistance, with their own qualification and disqualification eligibility criteria, which may affect young people (Leschke and Finn, 2016; Standing, 2000). Receipt of benefits is connected with various obligations, including registration, cooperation with authorities, accepting job offers and participation in activation measures.

Generous and reasonably long unemployment protection allows people to be out of work without suffering a grave reduction of their income. This can help them to find a better job, but it may prolong their unemployment spell (see Caliendo et al., 2009; Van Ours and Vodopivec, 2006). Entitlement to unemployment insurance is often conditional on previous employment and/ or contribution records, which may exclude young people (Chung, 2016; Leschke and Finn, 2016). People working on specific types of contracts can be excluded from claiming unemployment insurance (Leschke and Finn, 2016). There may be an age or family test leading to different conditions for older or younger workers (Leschke and Finn, 2016; Standing, 2000). For example, regarding job departure, there may be a reduction or denial of benefits for people who leave their jobs voluntarily (Standing, 2000).

It is also relevant how unemployment protection is connected to income security, as captured by objective as well as subjective indicators. Income security can depend on entitlement, (dis)qualifying conditions and the level of benefits in the event of eligibility (Standing, 2000). There is a trend in some countries to leave responsibility for the income security of young people to their families (Cinalli and Giugni, 2013). We have not found a study that has measured the impact of unemployment protection for young people (controlling for other factors). However, we do know that the general level of poverty and subjective material deprivation increased amongst young people in many EU countries between 2007 and 2011 (see Aassve et al., 2013). More generous unemployment protection is linked with a higher level of subjective perception of job security (Anderson and Pontusson, 2007; Clark and Postel-Vinay, 2009), with this relationship being stronger for temporary workers (Clark and Postel-Vinay, 2009). Workers who feel they are in insecure employment are more in favour of higher unemployment benefits than workers who feel more secure (Paskov and Koster, 2014).

Unemployment protection systems are expected to provide effective protection against the risks of income poverty and material deprivation for young people entering the labour market or changing jobs. Better unemployment protection is also associated with a stronger emphasis on 
an enabling/human-capital development approach to ALMPs than on the work-first approach (see Gallie and Paugam, 2000a, 2000b).

Gallie and Paugam (2000a, 2000b) have suggested a typology of unemployment policy regimes in relation to young people where they reflect on the role of unemployment protection. They distinguished between four different types of unemployment policy regime: universalistic, employment-centred, liberal/minimal and sub-protective. The universalistic regime provides comprehensive coverage and high unemployment compensation. Protection is substantial for all, including women and young people. The employment-centred regime provides a much higher level of compensation, but it is based on selective principles of eligibility for compensation. It can be expected that women and young people will be particularly disadvantaged. The liberal regime provides better protection due to higher coverage, but the benefit level is low and is means tested. In the sub-protective regime, few of the unemployed receive benefits and, when they do, the amount is low (Gallie and Paugam, 2000a, 2000b).

\section{CONCLUSIONS}

Our discussion of the four policy fields has shown how they are relevant for the transitions of young people into the labour market. In education the following aspects are crucial: the types of skills that are provided, the quality of education, whether the education system is flexible or path defined, and its ability to provide a secure education trajectory. ALMPs are characterized by the scope and profile of the measures (especially upskilling leading to meaningful jobs is important) and their targeting of young people. As regards employment protection, the degree of labour market dualism is important: whether or not young people start their careers in jobs with a low level of protection. Similarly, unemployment protection is important for securing a livelihood during job-search periods. The interactions and synergy of the policy fields and their cross-sectional coordination seem to be important for the effective labour market inclusion of young people. It was shown that it is fruitful to approach the interaction of the policy fields from the perspective of the employment regime when different policy fields and instruments are interconnected by common policy objectives and principles. The stylized typology of the emerging policy packages can be characterized as follows (Table 7.2).

In the inclusive regime, human-capital development dominates. A welldeveloped education system oriented towards general skills is effectively complemented with ALMP measures with a strong emphasis on upskilling and vocational training. The measures are supportive for those who are 


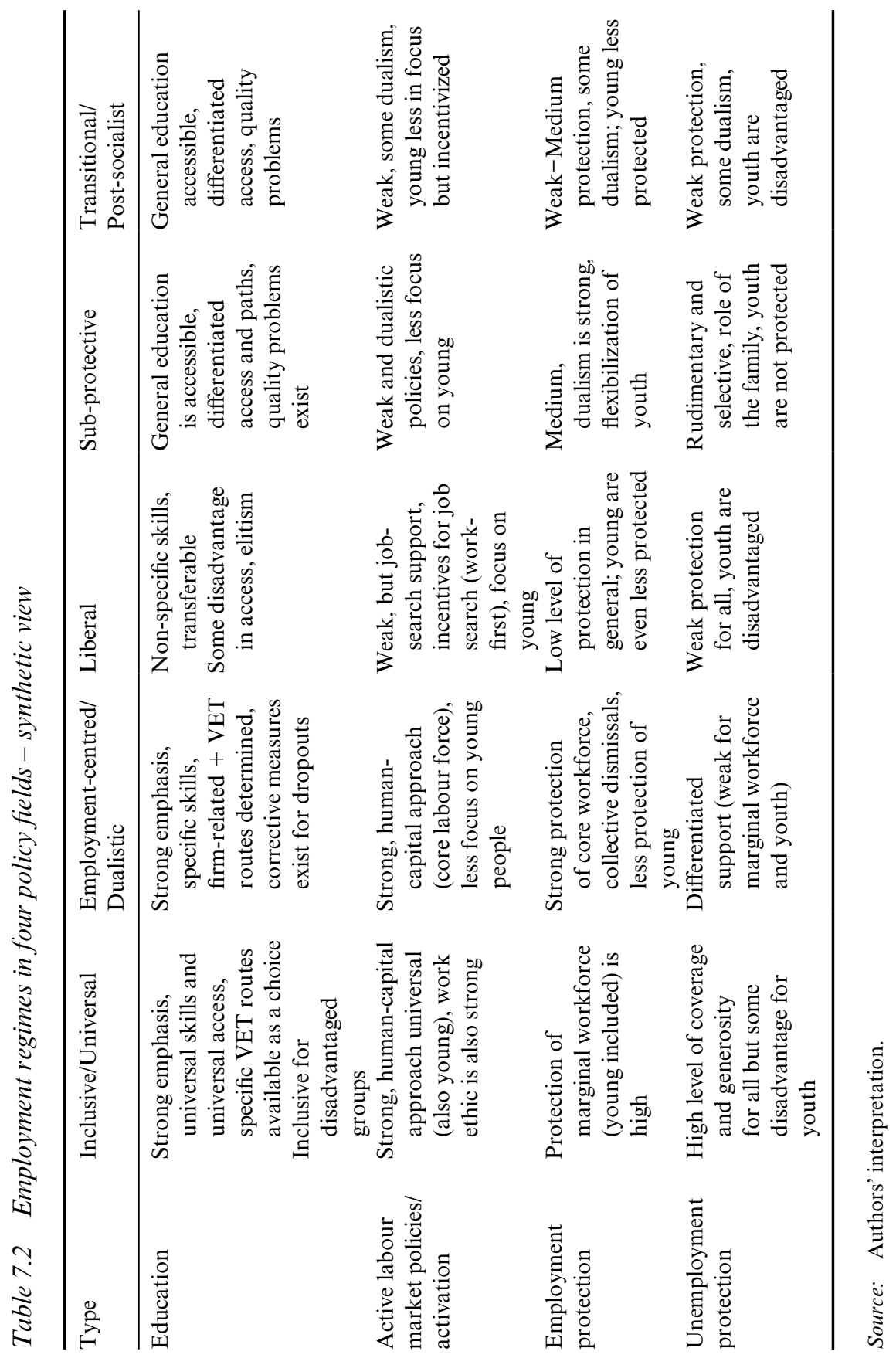


disadvantaged in access to education and the labour market. Employment protection is not very differentiated across labour force categories, nor is it too rigid; instead, labour force mobility is supported. Unemployment protection is generous in order to prevent human capital losses, and the work ethic is also kept at a high level through activation measures. The principles of functional flexicurity are consistently and universally applied in this regime, enabling the effective integration of young people into the labour market.

In the employment-centred regime, the human-capital development approach is also quite developed. Its dualist education system strongly emphasizes vocational specificity and professional paths, while ALMPs aim at the protection of existing jobs and the preservation of human capital in companies. Employment/job protection as well as the unemployment protection of the core labour force are both strong; however, young people/entrants are disadvantaged. There is a smooth school-to-work transition through vocationally distinct paths, but fewer options in the event that certain jobs are not available or in times of structural changes.

Similar to the inclusive regime, the education system in the liberal regime is generally oriented towards transferable skills, although it may be rather elitist regarding its access to and quality of education. Workfirst incentivizing activation measures prevail over human-capital development, combined with workfare measures and job-search assistance. Employment and unemployment protection are generally weak. In the primary labour market, interventions are deliberately minimized to a level that is needed for boosting labour supply to adjust to labour demand. Young people are disadvantaged by their lower competitiveness and are pushed to accept precarious, marginal jobs.

In the sub-protective regime the education system is less developed, of lower quality, less specific and centralized. ALMPs are less developed either in human-capital development measures or in work-first/activation measures. In times of recession, job creation is prioritized over humancapital development. While the core labour force is well protected, the marginal labour force, such as young people/entrants, is flexibilized. Unemployment protection is less generous and dualistic, to the disadvantage of young people, resulting in their dependence on their families.

The transitional/post-socialist employment regime appears to be a hybrid of the employment-centred and liberal regimes, representing a poorer version of both. The education system provides some vocational specificity, as well as broadly accessible general education at least at the secondary level, but the quality is problematic, as is the link to the labour market. Because ALMPs are less developed, the work-first approach clearly prevails. Employment protection as well as unemployment protection are provided 
at a modest level and bear some features of dualism. Young people are disadvantaged in relation to both jobs and unemployment protection.

In general, it seems that a stronger emphasis on the enabling/humancapital development approach requires more complex but individualized policies and hence more cooperation and horizontal, sectoral and vertical policy coordination. This trend is stronger when more attention is paid to the needs of the clients.

In Hora et al. (Chapter 8 this volume) and other chapters, the inclusive regime is represented by Norway; the employment-centred regime by Germany and Switzerland; the liberal regime by the United Kingdom; the sub-protective regime by Greece and Spain; and, finally, the transitional/ post-socialist regime by Bulgaria, the Czech Republic and Poland.

\section{REFERENCES}

Aassve A, Cottini E and Vitali A (2013) Youth prospects in a time of economic recession. Demographic Research 29(36): 949-62.

Anderson C and Pontusson J (2007) Workers, worries and welfare states: Social protection and job insecurity in 15 OECD countries. European Journal of Political Research 46(2): 211-37.

Avdagic S (2015) Does deregulation work? Reassessing the unemployment effects of employment protection. British Journal of Industrial Relations 53(1): 6-26.

Barbieri P and Cutuli G (2015) Employment protection legislation, labour market dualism, and inequality in Europe. European Sociological Review 32(4): 501-16.

Bathmaker A-M (2003) The expansion of higher education: A consideration of control, funding and quality. In: Bartlett S and Burton D (eds) Education studies. Essential Issues. London, UK: Sage, pp.169-89.

Berloffa G, Matteazzi E, Sandor A and Villa P (2016) Youth employment security and labour market institutions: A dynamic perspective. ECINEQ Working Paper no. 392. Verona: Society for the Study of Economic Inequality.

Bol T and Van de Werfhorst HG (2013) The measurement of tracking, vocational orientation, and standardization of educational systems: A comparative approach. AIAS, GINI Discussion Paper no. 81. Amsterdam: Institute for Advanced Labour Studies.

Bonoli G (2010) The political economy of active labour market policy. Politics \& Society 4(38): 435-57.

Breen R (2005) Explaining cross-national variation in youth unemployment: Market and institutional factors. European Sociological Review 21(2): 125-34.

Brown P, Lauder H and Ashton DN (2011) The Global Auction: The Broken Promises of Education, Jobs and Incomes. Oxford, UK: Oxford University Press.

Caliendo M, Tatsiramos K and Uhlendorff A (2009) Benefit duration, unemployment duration and job match quality: A regression-discontinuity approach. IZA Discussion Paper no. 4670. Bonn: Institute for the Study of Labor.

Cazes S and Nesporova A (2004) Labour markets in transition: Balancing flexibility and security in Central and Eastern Europe. Revue de l'OFCE 14(5): 23-54.

Chung H (2016) Dualization and subjective employment insecurity: Explaining 
the subjective employment insecurity divide between permanent and temporary workers across 23 European countries. Economic and Industrial Democracy: 1-30. Epub ahead of print 11 July 2016. DOI: 10.1177/0143831X16656411.

Chung $\mathrm{H}$ and Van Oorschot W (2011) Institutions vs. market forces: Explaining the employment insecurity of European individuals during (the beginning of) the financial crisis. Journal of European Social Policy 21(4): 287-301.

Cinalli M and Giugni M (2013) New challenges for the welfare state: The emergence of youth unemployment regimes in Europe? International Journal of Social Welfare 22(3): 290-99.

Clark A and Postel-Vinay F (2009) Job security and job protection. Oxford Economic Papers 61(2): 207-39.

Dingeldey I (2007) Between workfare and enablement? The different paths to transformation of the welfare state: A comparative analysis of activating labour market policies. European Journal of Political Research 46(6): 823-51.

Eichhorst W, Kaufmann O, Konle-Seidl R and Reinhard H-J (2008) Bringing the jobless into work? An introduction to activation policies. In: Eichhorst W, Kaufmann $\mathrm{O}$ and Konle-Seidl R (eds) Bringing the Jobless into Work? Experiences with Activation Schemes in Europe and the US. Berlin: Springer, pp. 1-16.

Eichhorst W, Rodríguez-Planas N, Schmidl R and Zimmermann KF (2015) A road map to vocational education and training in industrialized countries. Industrial Relations and Labour Review 68(2): 314-47.

Esping-Andersen G (1999) Social Foundations of Postindustrial Economies. Oxford, UK: Oxford University Press.

Gallie D (2007a) Production regimes and the quality of employment in Europe. Annual Review of Sociology 33: 85-104.

Gallie D (2007b) Production regimes, employment regimes, and the quality of work. In: Gallie D (ed.) Employment Regimes and the Quality of Work. Oxford, UK: Oxford University Press, pp. 1-34.

Gallie D (2011) Production regimes, employee job control and skill development. LLAKES Research Paper no. 31. London, UK: Centre for Learning and Life Chances in Knowledge Economies and Societies. http://www.llakes.org (accessed 30 April 2018).

Gallie D (2013) Economic crisis, the quality of work, and social integration: Issues and context. In: Gallie D (ed.) Economic Crisis, Quality of Work, and Social Integration. Oxford, UK: Oxford University Press, pp. 1-29.

Gallie D and Paugam S (2000a) The experience of unemployment in Europe: The debate. In: Gallie D and Paugam S (eds) Welfare Regimes and the Experience of Unemployment in Europe. Oxford, UK: Oxford University Press, pp. 1-22.

Gallie D and Paugam S (2000b) The social regulation of unemployment. In: Gallie $\mathrm{D}$ and Paugam S (eds) Welfare Regimes and the Experience of Unemployment in Europe. Oxford, UK: Oxford University Press, pp. 351-74.

Gangl M (2001) European patterns of labour market entry: A dichotomy of occupationalized versus non-occupationalized systems? European Societies 3(4): 471-94.

Gebel M (2010) Early career consequences of temporary employment in Germany and the UK. Work, Employment and Society 24(4): 641-60.

Gebel M (2013) Is a temporary job better than unemployment? A cross-country comparison based on British, German and Swiss panel data. SOEP Papers no. 543. Berlin: German Institute for Economic Research (DIW).

Gebel M and Giesecke J (2016) Does deregulation help? The impact of employment 
protection reforms on youths' unemployment and temporary employment risks in Europe. European Sociological Review 32(4): 486-500.

Hadjivassiliou KP, Tassinari A, Eichhorst W and Wozny F (2016) Assessing the performance of school-to-work transition regimes in the EU. IZA Discussion Paper no. 10301. Bonn: Institute of Labor Economics.

Hall PA and Soskice D (eds) (2001) Varieties of Capitalism: The Institutional Foundations of Comparative Advantage. Oxford, UK: Oxford University Press.

Harcourt M, Wood G and Roper I (2007) The importance of legislated employment protection for worker commitment in coordinated market economies. Journal of Economic Issues 41(4): 961-80.

Iversen T and Stephens JD (2008) Partisan politics, the welfare state, and three worlds of human capital formation. Comparative Political Studies 41(4/5): 600-37.

Leschke J and Finn M (2016) Tracing the interface between numerical flexibility and income security for European youth during the economic crisis. STYLE Working Paper no. 10.1a. Brighton, UK: CROME, University of Brighton.

Lødemel I and Trickey H (eds) (2001) An Offer You Can't Refuse. Workfare in International Perspective. Bristol, UK: The Policy Press.

Lundahl L (2011) Paving the way to the future? Education and young Europeans' paths to work and independence. European Educational Research Journal 10(2): $168-79$.

Noelke C (2016) Employment protection legislation and the youth labour market. European Sociological Review 32(4): 471-85.

Paskov M and Koster F (2014) Institutions, employment insecurity and polarization in support for unemployment benefits. Journal of European Social Policy 24(4): 367-82.

Pohl A and Walther A (2007) Activating the disadvantaged. Variations in addressing youth transitions across Europe. International Journal of Lifelong Education 26(5): 533-53.

Raffe D (2011) Cross-national differences in education-work transitions. In: London M (ed.) The Oxford Handbook of Lifelong Learning. New York: Oxford University Press, pp. 312-28.

Scarpetta S (2014) Employment protection. IZA World of Labor no. 12. DOI: 10.15185/izawol.12.

Schofer E and Meyer JW (2005) The worldwide expansion of higher education in the twentieth century. American Sociological Review 70(6): 898-920.

Standing G (2000) Unemployment and Income Security. Geneva: International Labour Organization.

Van Ours J and Vodopivec M (2006) How shortening the potential duration of unemployment benefits affects the duration of unemployment: Evidence from a natural experiment. Journal of Labour Economics 24(2): 351-78.

Wallace C and Bendit R (2009) Youth policies in Europe: Towards a classification of different tendencies in youth policies in the European Union. Perspectives of European Politics and Society 10(3): 441-58.

Walther A (2006) Regimes of youth transitions: Choice, flexibility and security in young people's experiences across different European contexts. Young 14(2): 119-39.

West A and Nikolai R (2013) Welfare regimes and education regimes: Equality of opportunity and expenditure in the EU (and US). Journal of Social Policy 42(3): 469-93. 